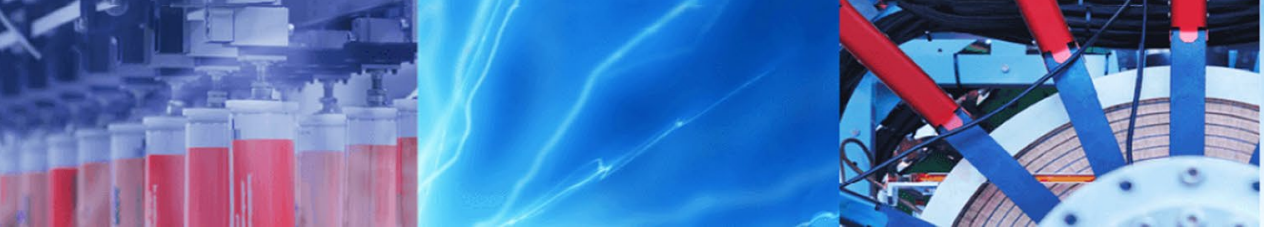

Research Article

\title{
Optimal design of solar-wind hybrid system-connected to the network with cost-saving approach and improved network reliability index
}

\author{
Esmaeil Eslami ${ }^{1} \cdot$ Mehrdad Ahmadi Kamarposhti $^{2}$ (1)
}

Received: 9 August 2019 / Accepted: 15 November 2019 / Published online: 30 November 2019

(c) Springer Nature Switzerland AG 2019

\begin{abstract}
In this paper, the optimal design of a grid-connected the hybrid energy system for a sample area in the north Iran is studied. A new innovative cost-based objective function is proposed which is combination of life cycle cost and reliability cost. Also, loss of power supply probability (LPSP) criteria, is considered as constraint for ensuring at the same time certain level of system reliability. Designing process is implemented in such a way that the total cost of the system reaches its minimum. For this purpose, a modified version of Bee algorithm has been proposed to achieve this goal. In order to carry out studies, the actual sample system, whose data has been available, has been studied. The results indicate the good performance of proposed hybrid system to reduce system cost.
\end{abstract}

Keywords Modified bee algorithm · Hybrid system · Solar-wind system · PSO · DE

\section{Introduction}

Renewable energy sources such as wind and solar have grown dramatically due to the need to preserve fossil fuel resources for future generations and to prevent the burning environmental damage caused by them, and they can be found near utilization centers in order to decrease losses [1-3]. For improve renewable resources performance, the sources work together and complement each other, known as hybrid systems. Because the power systems with two or more different sources of energy, they are more reliable than systems with one source. The hybrid of photovoltaic and wind turbine systems can provide a wide range of facilities. But these systems should be more robust and flexible in terms of power generation [4]. One solution to this is the optimal design of solar and wind combined systems. Various purposes for designing hybrid systems such as reducing costs, reducing emissions, improving power quality indicators, and improving reliability are considered [5].

Designing optimal and determining the optimum capacity of different sources of energy production and with different approaches in these references has been discussed. In recent years, the use of renewable energy in order to generate energy and supply to the grid has increased steadily. For example, in [6], heuristic based algorithm is proposed for optimal design of independent solar and wind power system incorporating load forecasting. In [7], the design of a hybrid solar-wind and battery system, and considering the probability of losing power source (LPSP). In this paper, a differential evolution algorithm has been used. In [8], a hybrid search optimization algorithm is used for optimal design of a solar wind power plant with hydrogen sources is presented. In designing procedure, weather forecasting is also used for accurate results of simulations. In [9], a new optimization method called Swine Flu modeling based on quarantine optimization is

Mehrdad Ahmadi Kamarposhti, mehrdad.ahmadi.k@gmail.com; m.ahmadi@jouybariau.ac.ir| ${ }^{1}$ Department of Electrical Engineering, University College of Rouzbahan, Sari, Iran. ${ }^{2}$ Department of Electrical Engineering, Jouybar Branch, Islamic Azad University, Jouybar, Iran. 
proposed to determine the optimal location and size of dispersed generation units in the distribution network, in order to minimize the active power losses. The above algorithm performs randomization through quarantine and healing. The proposed algorithm has been applied to a 33-bus distribution system and the results of the proposed method have been compared with the results of the PSO optimization method. In [10], simulated annealingchaotic search algorithm-based optimization is proposed optimal design of reverse osmosis hybrid desalination system driven by wind and solar energies. The model used in this work includes a solar-powered hybrid system with energy storage, or the same battery. In [11], applications of distributed generation sources are integrated and transmitted separately from the network. Homer, HOGA and Ret Screen were introduced in this reference. DE algorithm, particle communities, and harmonic search of intelligent methods have led to the design of optimal hybrid power generation systems. In this paper, the main objective of the design of the hybrid power generation system in the studied grid, the reduction of energy production costs and the improvement of system reliability indices such as unprotected energy (ENS) and LPSP in design considerations are taken. Considering the cost per kilowatt of energy not provided and adding this cost to energy costs, a single target goal of energy will be created. As a result, the algorithm must minimize this function. On the other hand, according to the defined standards, the LPSP limit value should be less than the permissible limit ( $2 \%$ per year), which is applied as an optimization limitation in the problem [12].

In this paper a new comprehensive objective function is proposed for designing solar-wind hybrid system in an area in the north of Iran. The proposed objective function is a combination of life cycle cost and reliability cost. Also, reliability constraints are considered in the design process. A modified version of the bee algorithm is also proposed to solve the optimization problem.

The remainder of this article is presented in the second part of the study network. In the third section, the relationships required for modeling the proposed system are described, and in Sect. 4, the Bee algorithm is briefly described. In the fourth section, simulation results were presented in three scenarios. Finally, this article ends with the results and conclusions in Sect. 5 .

\section{Power generation hybrid system}

In recent years, distributed sources have been used abundantly in distributed electrical energy networks to reduce losses, improve reliability, reduce environmental pollution, and reduce energy costs, and so on. According to the statistics, among the distributed sources of production, solar and wind sources have been used more than other sources. The reason for this is the availability of solar and wind power in most parts of the world, as well as their lack of pollution. But the issue that is of great importance in this area is the power to extract solar and wind resources depending on the intensity of the sun's radiation and wind speed in that area. Now, if there is not enough sun in the hours of daylight or wind speed, these two power supplies will not be produced. By combining solar, wind and solar resources together, a hybrid power generation system can provide more reliable reliability than systems with a source [13]. It can be connected to the power grid so that there can be power exchange with the network. In Fig. 1, a hybrid power generation system is shown in which solar and wind resources are used as two sources of distributed generation that are responsible for supplying the region. The surplus power will be sold to the grid and in the event of a lack of power; the network will be used to supply the required electrical energy. In this system, meters are used to determine the amount of power exchanged with the network and load. One of the challenges ahead in power generation hybrid systems is the optimal size of each resource, which is strongly dependent on the amount of load in the area and its geographical condition [14]. The number of solar panels and the number of wind turbines used to minimize costs, in addition to supply, is a completely non-linear problem.

\section{Objective function and constraints}

The purpose of the design of the solar hybrid winding system for the studied network is to determine the number of solar panels and wind turbines with the aim of reducing energy costs and minimizing the cost of energy due to the energy not provided in the network. The total cost of the proposed system includes the total initial investment costs,

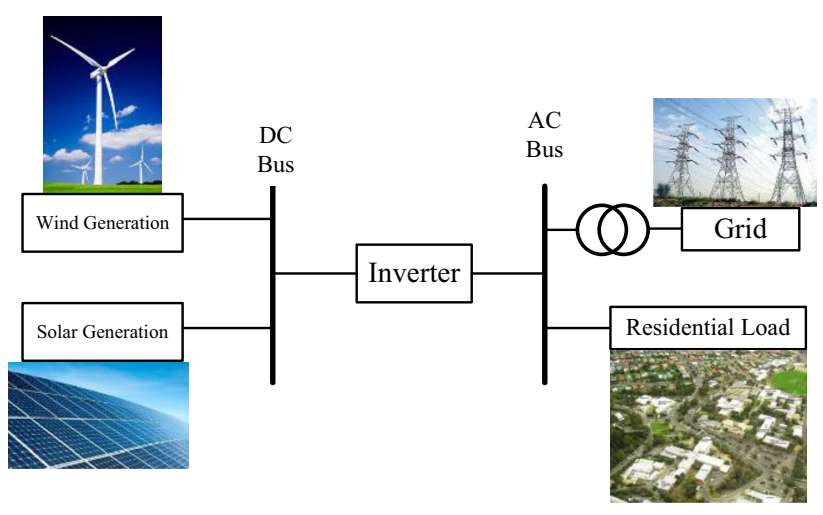

Fig. 1 The grid model studied 
the unprotected cost of energy and the net present value of all operating and maintenance costs [15]. This includes the replacement cost energy not supply cost (SCOC) and residual value of each component of the system plus the difference between the present value of the cost and the revenue from the delivery of power to the network, which is the cost function in the form of Eq. (1):

$$
\begin{aligned}
\min \mathbf{C}_{\mathrm{T}}= & \sum_{i \in P V, W}\left(\mathrm{I}_{\mathrm{i}}+\mathrm{R}_{\mathrm{NPV}_{-} \mathrm{i}}+\mathrm{OM}_{\mathrm{NPV}_{-} \mathrm{i}}-\mathrm{S}_{\mathrm{NPV}_{-} \mathrm{i}}\right) \\
& +\mathrm{P}_{e} * C_{e}+\mathrm{P}_{\mathrm{b}} * \mathrm{C}_{\mathrm{a}}-\mathrm{P}_{\mathrm{s}} * \mathrm{I}_{\mathrm{a}}+\mathrm{SCOC}
\end{aligned}
$$

The variable to be calculated is the total area of the solar panels and the swept surface of the wind turbine blades represented by the $A_{p v}$ and $A_{w}$ variables per square meter. Therefore, the total setup cost is:

$I_{P V}=\alpha_{P V} * A_{P V}=c_{1} * A_{P V}$

It is worth noting that the $\mathrm{N}$-year evaluation horizon of the project is equivalent to the useful life of a solar panel $\left(L_{p v}\right)$, so the cost of replacing this component from the system is zero. $\left(R_{N P V \_P V}=0\right)$. The useful life of wind turbines $\left(L_{W}\right)$ is usually less than that of solar panels (here it is equal to $N$ ). Therefore, additional investment for wind turbines will be required before the horizon of the project is completed. The number of times the $\mathrm{N}$-year horizon of the wind turbine project should be replaced is equal to $X_{W}=N / L_{W}[16]$. If $a_{W}$ is the initial investment in the current time in dollars per square meter, then the investment in year $y$ is equal to:

$\alpha_{\mathrm{w}} *\left(\frac{1+\varepsilon_{\mathrm{w}}}{1+\mathrm{r}}\right)^{y}$

$\mathrm{I}_{\mathrm{W}}+\mathrm{R}_{\mathrm{NPV} \_\mathrm{W}}=\alpha_{\mathrm{W}} * \mathrm{~A}_{\mathrm{W}} * \sum_{\mathrm{X}=1}^{\mathrm{X}_{\mathrm{W}}}\left(\frac{1+\varepsilon_{\mathrm{W}}}{1+\mathrm{r}}\right)^{(\mathrm{X}-1) \mathrm{L}_{\mathrm{W}}}=\mathrm{c}_{4} * \mathrm{~A}_{\mathrm{W}}$

Total Net Value Total O\&M costs are:

$$
\mathrm{OM}_{\mathrm{NPV}}=\alpha_{\mathrm{OMPV}} * \mathrm{~A}_{\mathrm{PV}} * \sum_{k=1}^{\mathrm{N}}\left(\frac{1+\varepsilon_{\mathrm{PV}}}{1+\mathrm{r}}\right)^{\mathrm{k}}=c_{2} * A_{P V}
$$

$$
\begin{aligned}
\mathrm{OM}_{\mathrm{w}} & =\alpha_{\mathrm{OMw}} * \mathrm{~A}_{\mathrm{W}} \mathrm{OM}_{\mathrm{NPV}_{\mathrm{W}}} \\
& =\alpha_{\mathrm{OMw}} * \mathrm{~A}_{\mathrm{W}} * \sum_{k=1}^{N}\left(\frac{1+\varepsilon_{\mathrm{w}}}{1+\mathrm{r}}\right)^{\mathrm{k}}=c_{5} * A_{W}
\end{aligned}
$$

Total revenue from resale and total net worth total revenues from resale are equal to:

$$
S_{N P V_{-} P V}=S_{P V} * A_{P V} *\left(\frac{1+\delta}{1+r}\right)^{N}=c_{3} * A_{P V}
$$

The resale price of the $S_{d}$ wind turbine in dollars per square meter during its useful life is linearly reduced from $a_{w}$ to $S_{w}$.

$S_{d}=\left(\frac{S_{W}-\alpha_{W}}{L_{W}}\right) * y_{d}+\alpha_{w}$

$$
\begin{aligned}
S_{N P V \_W}= & S_{W} * A_{W} * \sum_{x=1}^{X_{w}-1}\left(\frac{1+\delta}{1+r}\right)^{x * L_{W}} \\
& +S_{d} * A_{W} *\left(\frac{1+\delta}{1+r}\right)^{N}=c_{6} * A_{W}
\end{aligned}
$$

Assuming a constant consumption of energy per year, the total net value of purchasing energy from the network will be as follows:

$\boldsymbol{P}_{N P V b} * C_{a}=C_{A} \sum_{k=1}^{N}\left(\frac{1+\delta}{1+r}\right)^{k}=C_{7} * C_{a}$

If the amount of energy sold to the network is equal to $E_{s}$ and the annual energy sales to the $P_{s}$ network are in $\$ / \mathrm{kWh}$, then the annual energy sales to the network are equal to $I_{a}=P_{s} . E_{s}$, so the total net sales value of energy sales to the network is equal to With:

$\boldsymbol{P}_{N P V s} * I_{a}=I_{A} \sum_{k=1}^{N}\left(\frac{1+\delta}{1+r}\right)^{k}=C_{8} * I_{a}$

The LPSP limitation for a solar-hybrid hybrid system in the time period $\mathrm{T}$ is calculated from the following equation. The amount of $\overline{L P S P}$ should not be less than the amount considered in this article is $2 \%$ [17].

$\operatorname{LPSP}=\frac{\sum_{t=1}^{T} P_{\text {deficit }}(t) \cdot \Delta t}{\sum_{t=1}^{T} P_{\text {demand }}(t) \cdot \Delta t} \leq \overline{\operatorname{LPSP}}$

In Fig. 2, the stack-to-step simulation steps and the LPSP control are shown in the flowchart.

\section{Under study network}

The studied grid is a residential town with 15 households located on the outside of the city of Sari with a geographical location of $36^{\circ} 33^{\prime} 48^{\prime \prime} N$, 530. $03^{\prime} 36^{\prime \prime}$ E. In Fig. 3, the geographic location of the target area is shown. It should be noted that the town has access to the national electricity grid and only used to reduce costs and improve the reliability of distributed sources of energy.

The amount of consumption of the city at $8760 \mathrm{~h}$ (for one year) is shown in Fig. 4.

The data on the amount of solar radiation and wind speed in the studied geographic region have been 


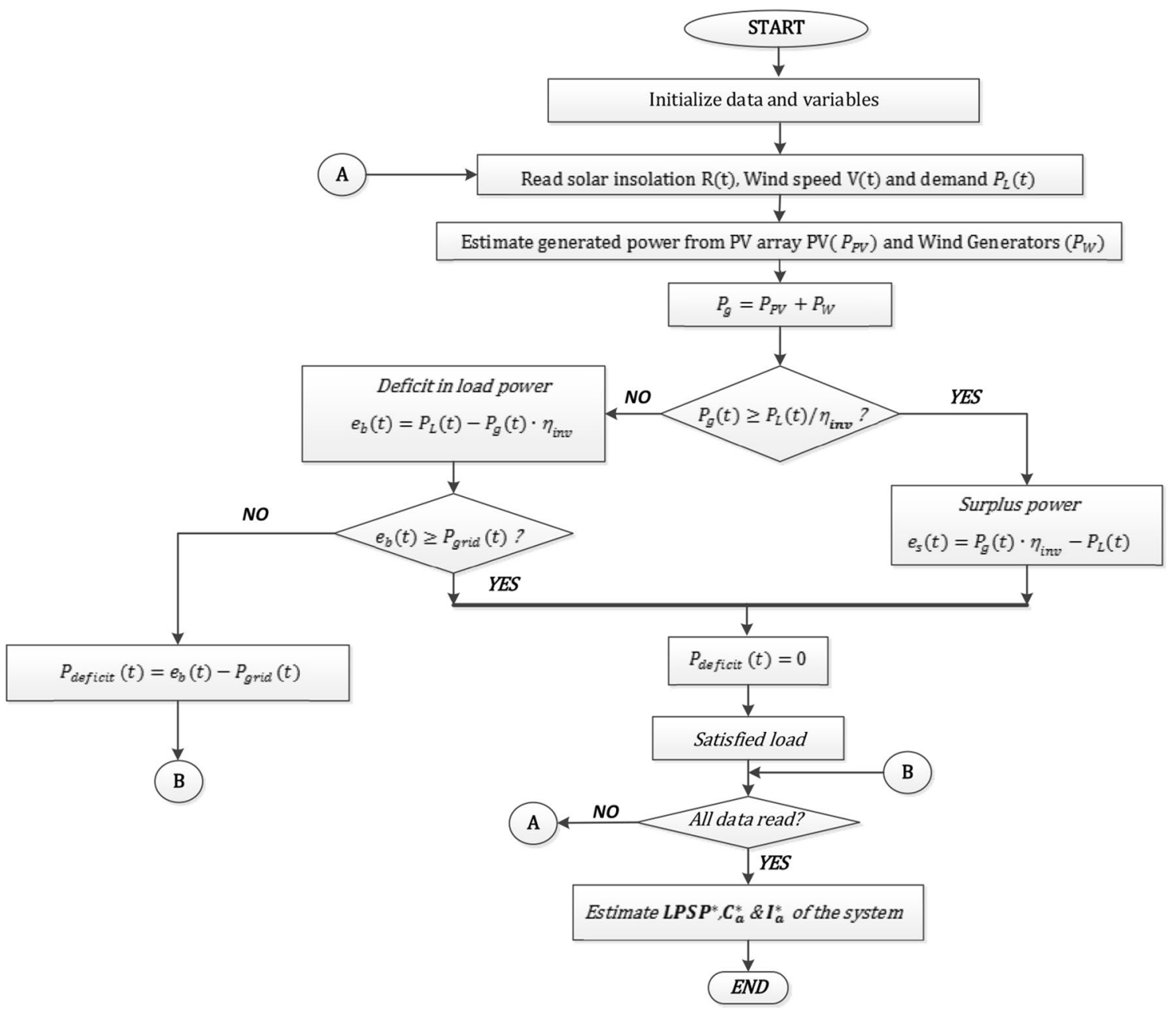

Fig. 2 Flowchart simulation system

Fig. 3 The study area

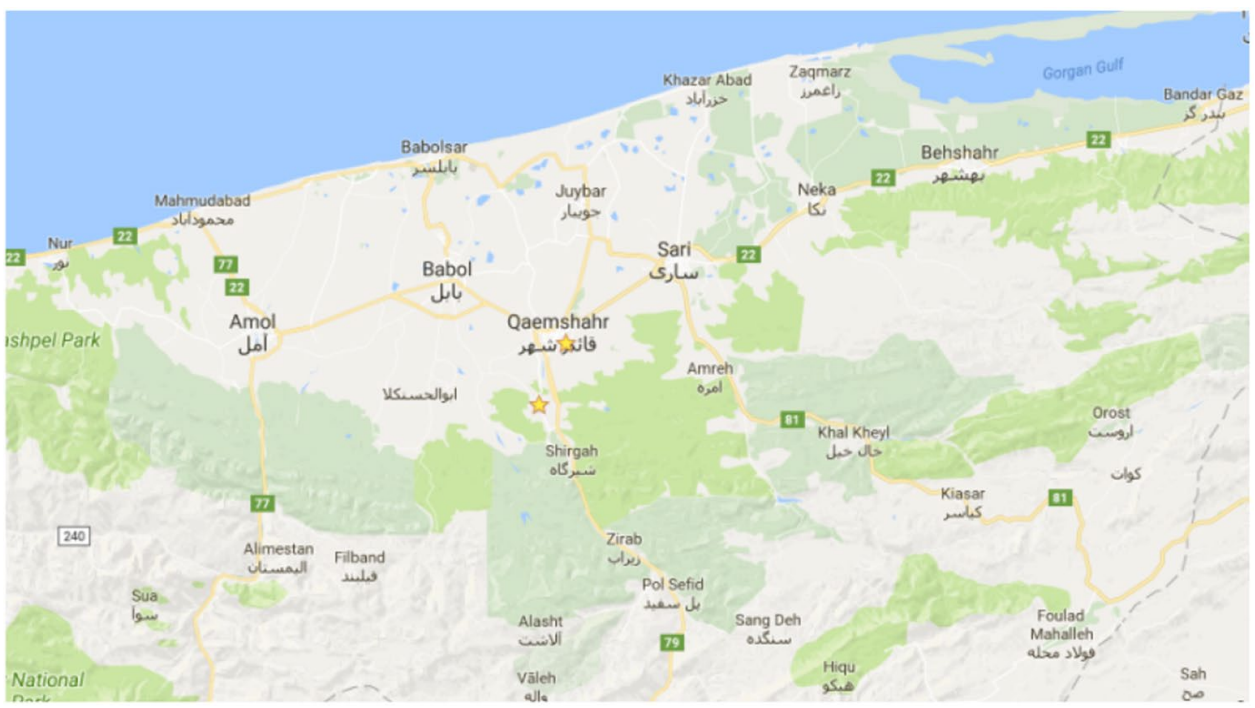


obtained for 1 year and hourly hours using the Homer software. The average solar radiation and wind speed in different months for the region studied in the study area are shown in Figs. 5 and 6.

The average solar radiation in the region is about $4 \mathrm{kWh} / \mathrm{m}^{2} / \mathrm{d}$ and the average wind speed is $1.73 \mathrm{~m} / \mathrm{s}$. Due to network constraints for power supply, its availability per hour with a normal function with an average of $40 \mathrm{kV}$ and a standard deviation of 20 is considered to provide the required data for $8760 \mathrm{~h}$. In Fig. 7, the network capacity is shown.
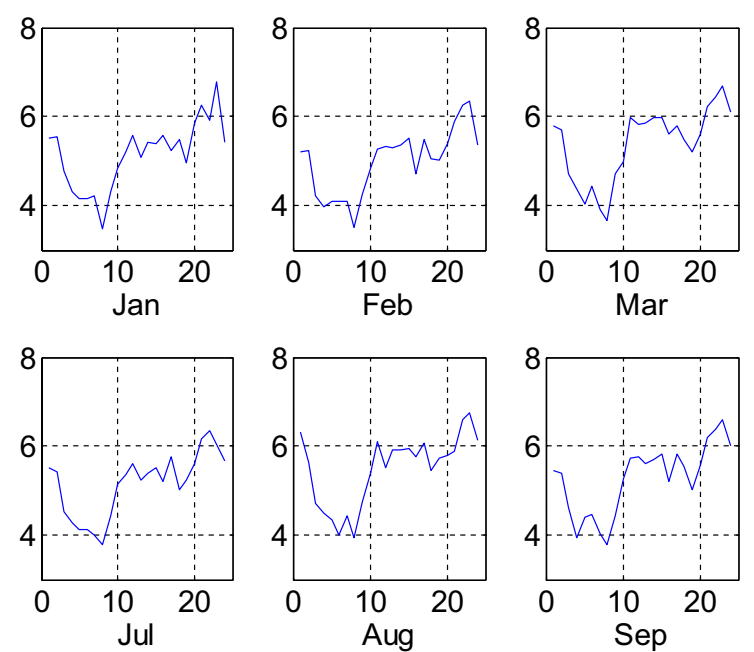
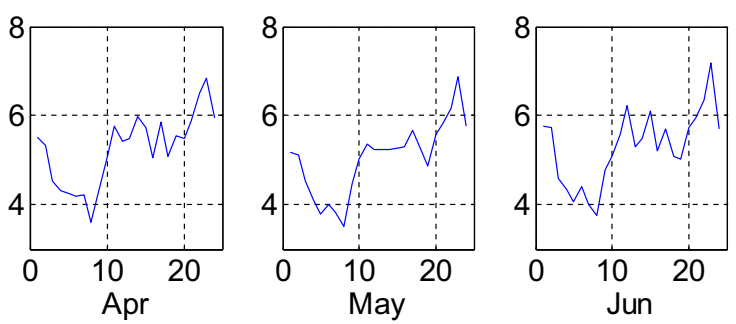

The bee colony algorithm was first introduced in 2005, an algorithm inspired by colonial bee behavior. Bee colony algorithm is used to solve continuous optimization problems and to find optimal values of a function or a combination of multivariate numeric functions. This method has better performance with less control parameters than other algorithms. The population in this algorithm consists of three groups of worker bees, treadmills and spectators. The first half of the population includes artificial laborer bees and the second half of the
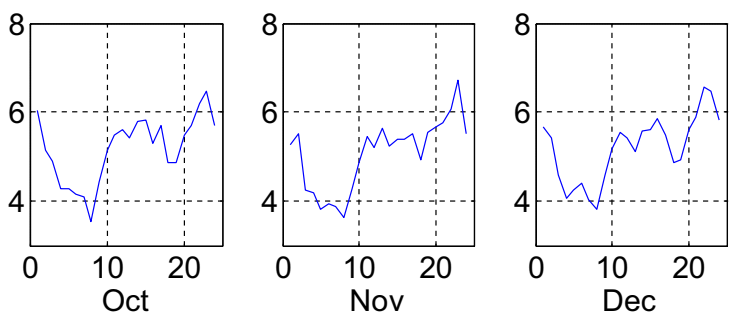

\section{Bee optimization algorithm}

Fig. 4 Average consumer charge

Fig. 5 The average monthly solar radiation

Fig. 6 Average monthly wind speed
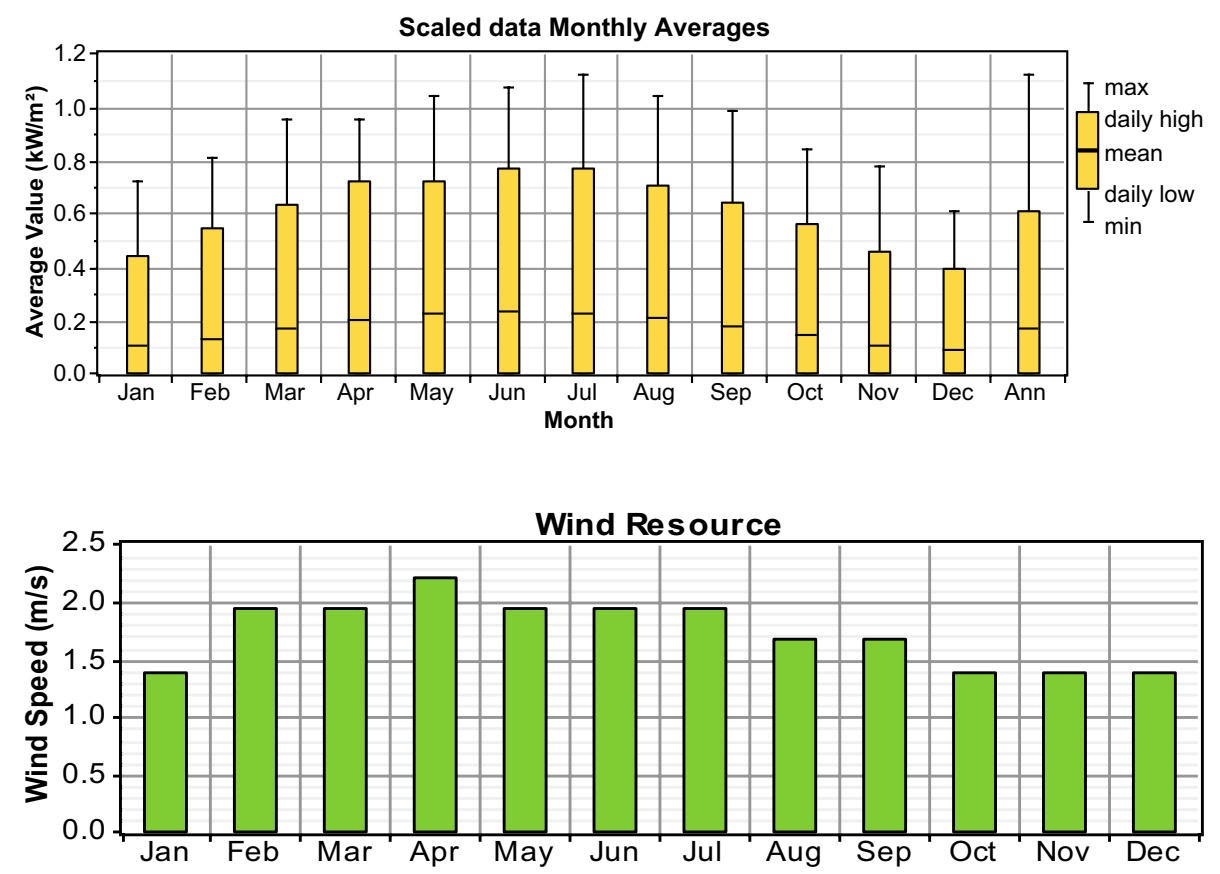

SN Applied Sciences A SPRINGER NATURE journal. 


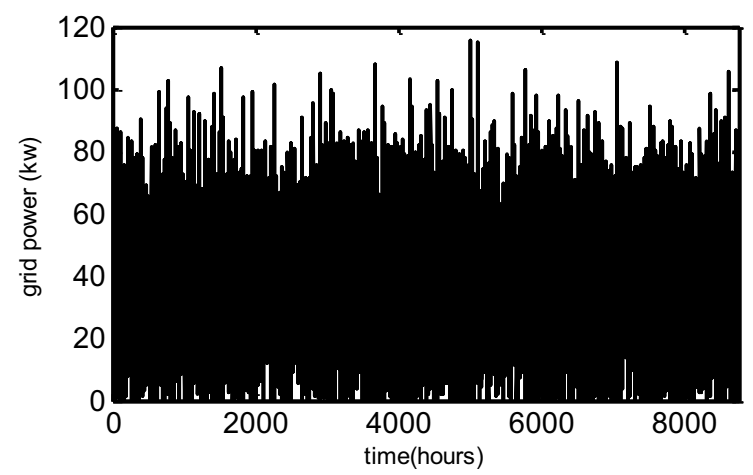

Fig. 7 Network power information

spectators' bees. For each food source, there is only one worker bee. In other words, the number of worker bees is equal to the number of sources of food around the hive. The beekeeper whose food supply is out of date becomes a predator bee [18].

In the first step, this algorithm is initialized. In this way, a set of food supply positions is randomly selected by the bees and their nectar values are determined. Then, these bees get into the hive and the nectar information is shared by each resource to the bees waiting in the dance area inside the hive.

$x_{i j}=x_{\min _{, j}}+\operatorname{rand}[0,1] \times\left(x_{\max _{, j}}-x_{\min _{, j}}\right)$

In Eq. (13), $x_{i j}$ the $j$-th variable is optimized from the ith most reliable solution to the problem of optimization, $x_{\min _{, j}}$ the lower limit of jth optimization variable, $x_{\max , j}$ the upper limit of jth optimization variable. Equation (13) states that optimization of random numbers for each variable is produced for each variable. After generating the initial population, the $A B C$ algorithm uses Eq. (14) to determine the fitness of each possible solution.

fit $_{i}=\left\{\begin{array}{cl}\frac{1}{1+f_{i}} & \text { if } f_{i} \geq 0 \\ 1+\left|f_{i}\right| & \text { if } f_{i}<0\end{array}\right.$

where $f_{i}$ is the cost of solving the possible $x_{i}$. Any worker or spectator bee may make changes to the available food source (possible resolution) in its memory and calculate its fitness. If the new solution's resolution is greater than the previous one, the new solution will be chosen and the old one will be forgotten; otherwise, it will keep the same solution in memory. In this algorithm, the new solution is the solution of the previous solution based on Eq. (15):

$v_{i j}=x_{i j}+\Phi_{i j}\left(x_{i j}-x_{k j}\right)$

The variable $k$ is generated randomly and must be different with $\mathrm{i}$. In this equation, $\Phi_{\mathrm{ij}}$ is a random number in the range $[1,-1]$. This number controls the production of food sources around $x_{i j}$, indicating a comparison of the two food sources by a bee. With this equation, the difference between $x_{i j}$ and $x_{k j}$ decreases, the deviation from the $x_{i j}$ location will also decrease. Therefore, as the search process approaches the optimal solution in search space, the deviation from the optimal solution decreases. In this equation, one dimension of one of the food sources is tried to be selected and, depending on the value of $\Phi$, in its direction or opposite direction. If the variable generated by Eq. (15) violates its limit, its value is replaced by an acceptable value. If it violates its upper limit, the upper limit value replaces it and if it violates the lower limit, the lower limit value is replaced. After exchanging information between the worker and spectator bees, spectators choose a food source with a probability that fits the quality of the nectar in the food source. This probability can be calculated in various ways, which are expressed in the equations [19].

$p_{i}=\frac{f i t_{i}}{\sum_{n=1}^{S N} f i t_{n}}$

$p_{i}=\frac{A \times f i t_{i}}{\max (f i t)+B}$

In Eq. (17), max (fit) is the largest amount of fitness among all possible solutions. The parameters $A$ and $B$ are constant values. According to the explanation of this section, we can say that the parameters of the number of food sources (SN), which is equal to the number of worker or spectator bees. You can use Flowchart Fig. 8 to design a hybrid power generation system using the Bee algorithm.

\section{Simulation results}

This section examines the results of simulation in Matlab software environment. In order to locate and determine the capacity of distributed generation sources in the studied network, three Bee algorithm (BA), Particle Swarm Optimization (PSO) and Differential Evolution (DE) algorithms have been used, taking into account the objective function. Table 1 shows the parameters of the used algorithms. Studies are repeated in three scenarios. In the first scenario, only wind turbines were used to supply power. In the second scenario, solar panels replaced the wind turbine, and in the third scenario, a solar-wind combination system was used. System cost values are calculated and compared with each other after optimization by the proposed algorithms.

The amount of energy requested from the network (Eb), the annual cost of energy purchased (Ca), the amount of LPSP constraint, the amount of unpaid energy fines (Ce), and 
Fig. 8 Flowchart of the bee cluster algorithm for the design of a power generation hybrid system
Table 1 The parameters of the algorithm BA, PSO and DE

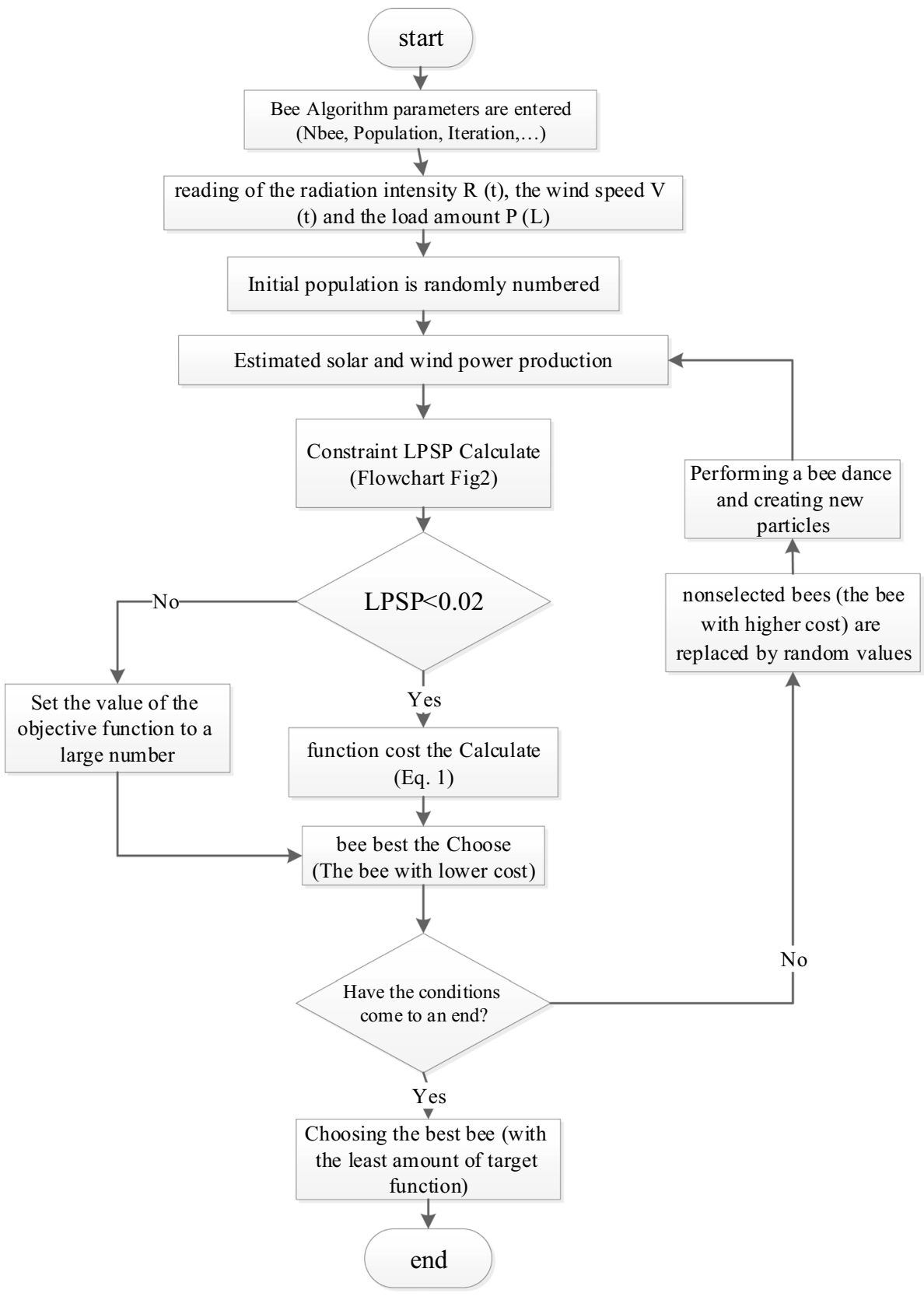

\begin{tabular}{lllllll}
\hline BA & nScoutBee & Maxlt & nSelectedSite & nEliteSite & $\begin{array}{c}\text { nSelected- } \\
\text { SiteBee }\end{array}$ & nEliteSiteBee \\
& 100 & 40 & 10 & 4 & 10 & 20 \\
PSO & pop & max_ite & $c 1=c 2$ & $\mathrm{w}$ & $\mathrm{V}_{\text {Min }}$ & $\mathrm{V}_{\text {Max }}$ \\
& 100 & 40 & 2 & 0.7 & 0.6 & 0.9 \\
DE & pop & max_ite & $\beta_{\min }$ & $\beta_{\max }$ & PCR & \\
& 100 & 40 & 0.4 & 0.8 & 0.6 & \\
\hline
\end{tabular}

the total cost of the system under basic conditions, in which there are no dispersed sources of production in the system., Is given in Table 2 .
The amount of energy demanded from the upstream network in one year of study is 45,625 kilowatt-hours per year. The annual cost of purchased energy is $174,560 \$$ and 
Table 2 Requested energy of the network and cost for the base mode

\begin{tabular}{lllll}
\hline Eb(KWh/year $)$ & $C_{a}(\$)$ & $C_{e}(\$)$ & LPSP & $C_{\mathrm{T}}(\$)$ \\
\hline 45,624 & 174,560 & 839.17 & 0.0368 & 228,120 \\
\hline
\end{tabular}

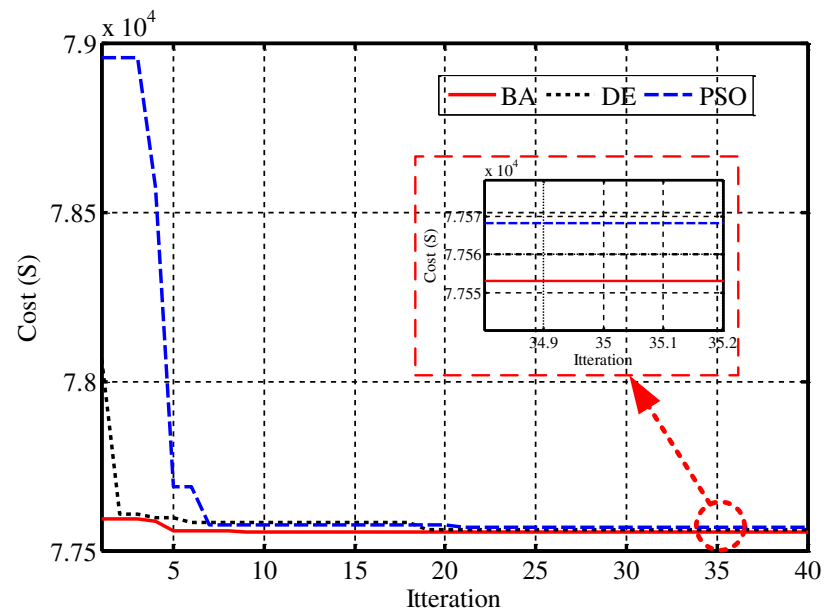

Fig. 9 The curve of the objective function changes in the first scenario

the non-energy fines are estimated at $840 \$$. The LPSP constraint is obtained in the absence of dispersed generation sources of $3.68 \%$. For a standard stand-alone system, the LPSP should be less than $2 \%$ in a year.

\subsection{The first scenario}

In this scenario, the design of a single-wind system connected to a nationwide power grid has been studied. For this purpose, BA, PSO and DE algorithms were used to optimize the design of this wind system. In Fig. 9, the curve of the cost function changes for the three algorithms is shown.

Figure 9 shows the performance of BA optimization algorithms (continuous red line) and PSO (Blue dash lines) and $\mathrm{DE}$ (Black dots). It can be seen that, as the response of the BA is optimized, the convergence of responses in this algorithm is more rapid. The final cost function for the BA algorithm is $192,908 \$$ while its value for both DE and PSO algorithms was $193,154 \$$ and $193,161 \$$ dollars, respectively. The results of optimization are summarized in Table 3.

The comparison and comparison of optimization results with three algorithms in Table 3 shows that the
BA algorithm has reached 147 wind turbines, while the algorithm of PSO aggregation has 140 numbers and the $D E$ algorithm has 161 numbers. The value of LPSP for the BA algorithm is 0.0198 and for the PSO and DE algorithms, respectively, is 0.02 and 0.019 , respectively. The annual cost of purchased energy for BA, PSO and DE algorithm are $8691 \$, 9109 \$$ and $8432 \$$ respectively. Also, SCOC is 657 $\$$ for $B A, 658 \$$ for PSO and $376 \$$ for DE algorithm. Although the energy demanded from the grid is less than two other algorithms using the DE algorithm, the cost of energy purchased from the network is reduced, but due to the higher number of wind turbines, the overall system costs have increased. According, the final cost of the system based on the bee colony algorithm is less than the proposed two alternative algorithms. Similarly, the annual amount of energy demanded by each home of the network was less than that calculated by calculating the bee colony algorithm.

\subsection{Second scenario}

In this scenario, it is assumed that there is only the possibility of installing solar panels in the study system. This time BA, PSO and DE algorithms have been used to design a power generation system. The comparisons of the performance of the algorithms are shown in Fig. 10 for finding optimal conditions. In this case, the convergence rate of the algorithms is roughly the same, although the response of the bee algorithm is more optimal than the other.

In the following, in Table 4, the results obtained from the optimization are presented by three algorithms.

The number of solar panels offered by the BA algorithm is 121 , while the number for both DE and PSO algorithms is 115 and 113 , respectively. The final cost of the system based on calculations of the bee colony algorithm is $135 \$$ less than the PSO algorithm calculations and $71 \$$ less than the DE algorithm. Also, the amount of energy that each house requests per year, and the annual cost of purchasing electrical energy from the network under the proposed conditions of the colony bee colony algorithm is less.

\subsection{Third scenario}

Each of the first and second scenarios has the advantages and disadvantages of using solar panels and wind turbines simultaneously to provide energy to minimize the existing
Table 3 Optimal design results in the first scenario

\begin{tabular}{lllllllll}
\hline & $\mathrm{A}_{W}\left(\mathrm{~m}^{2}\right)$ & Eb (KWh/year $)$ & $\mathrm{C}_{\mathrm{a}}(\$)$ & $\mathrm{SCOC}(\$)$ & $\mathrm{I}_{\mathrm{a}}(\$)$ & ENS (Kwh) & LPSP & $\mathrm{C}_{\mathrm{T}}(\$)$ \\
\hline BA & 138 & 26,145 & 8691 & 657 & 689 & 1722 & 0.0198 & 77,556 \\
PSO & 140 & 26,663 & 9109 & 685 & 612 & 1712 & 0.02 & 77,574 \\
DE & 161 & 25,125 & 8432 & 376 & 861 & 940 & 0.019 & 77,560 \\
\hline
\end{tabular}




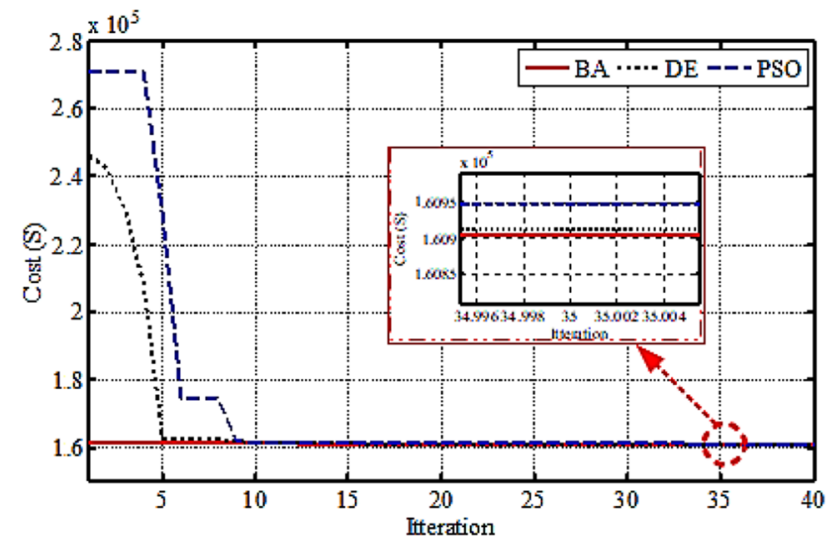

Fig. 10 The curve of the objective function changes in the second scenario

weaknesses while simultaneously taking advantage of both systems. In this scenario, the hybrid state has been investigated and the optimal number of solar panels and wind turbines has been obtained in the solar-wind hybrid system. The objective function change curve for three BA, PSO and DE community is shown in Fig. 11.

The optimal design results of the hybrid system are presented by three algorithms in Table 5 .

The comparison of the proposed optimal state with each algorithm shows that in the output of the PSO algorithm, due to the increase in the amount of wind turbine (compared with the output of the BA algorithm), due to the more uniform nature of the energy produced by wind turbines, the amount of energy Each house per year requests the network has declined proportionally. However, due to the intensity of radiation and wind speed in the study area, reducing the number of solar panels has reduced annual revenue from the sale of excess energy to the network in the output of the PSO. In the case that the annual cost of purchasing electrical energy from the network and the LPSP constraint is almost identical in both outputs, the total cost of the system as a function of the system objective in the proposed model of the BA algorithm has decreased by $358 \$$ compared to the output of the PSO algorithm.

\subsection{Numerical studies of the results}

Table 6 compares the baseline (without a power generation hybrid system) with three other power generation

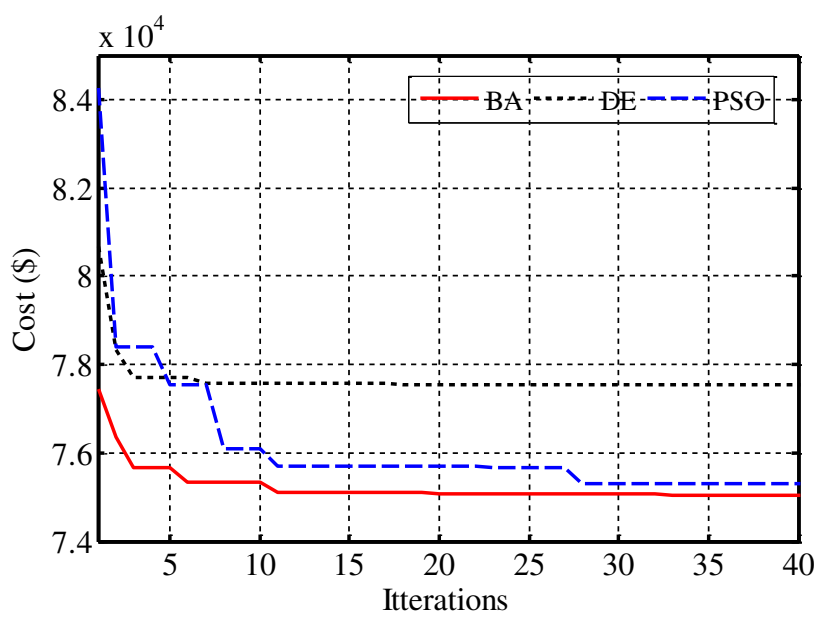

Fig. 11 The curve of the objective function changes in the third scenario

systems. In the base state (without installing distributed energy sources), there is the highest cost involved in purchasing energy from the network. The next most expensive scenario is the use of wind turbines. The lowest cost is the hybrid system, and the scenario of using the solar panel is only second. The annual amount of energy purchased per household from the network is in the bestexpected hybrid mode. In contrast to the wind turbine scenario, despite the final cost of the solar panel scenario, the annual energy demand is lower than the network due to the lack of available solar energy at hours the beginning and the end of the day. However, due to the amount of radiation in the study area, this weakness of the solar scenario is offset by increasing the revenue from the sale of excess energy to the network, so that in this section the solar scenario is even better than the hybrid state.

The Fig. 12 shows the cost of an optimally designed hybrid system for solar and wind divisions. In this chart, initial_investment represents the initial installation cost, replacement_cost replacement cost, $\mathrm{O}$ _M cost-of-charge and maintenance, and salvage_value value of the equipment's disposal at the end of the review period.

As shown, the installed solar panel suite, despite the initial cost, has a lower cost of replacing, operating and maintaining. In Fig. 13, the net present value and projected hybrid system revenues are shown.
Table 4 Optimal design results in the second scenario

\begin{tabular}{llllllll}
\hline & Npv & Eb (KWh/year) & $C_{\mathrm{a}}(\$)$ & SCOC $(\$)$ & $\mathrm{l}_{\mathrm{a}}(\$)$ & LPSP & $\mathrm{C}_{\mathrm{T}}(\$)$ \\
\hline BA & 121 & 27,700 & 9664 & 685 & 1593 & 0.02 & 166,291 \\
PSO & 113 & 28,007 & 9700 & 685 & 1392 & 0.02 & 166,426 \\
DE & 115 & 27,922 & 9663 & 685 & 1444 & 0.02 & 166,362 \\
\hline
\end{tabular}


Table 5 Optimal design results in the third scenario

\begin{tabular}{llllllllll}
\hline & $\mathrm{A}_{\mathrm{PV}}\left(\mathrm{m}^{2}\right)$ & $\mathrm{A}_{\mathrm{W}}\left(\mathrm{m}^{2}\right)$ & $\mathrm{Eb}(\mathrm{KWh} /$ year $)$ & $\mathrm{C}_{\mathrm{a}}(\$)$ & $\mathrm{SCOC}(\$)$ & $\mathrm{l}_{\mathrm{a}}(\$)$ & ENS $(\mathrm{Kwh})$ & LPSP & $\mathrm{C}_{\mathrm{T}}(\$)$ \\
\hline BA & 80 & 63 & 23,853 & 7872 & 226 & 1192 & 565 & 0.0182 & 75,105 \\
PSO & 67 & 74 & 23,716 & 7812 & 210 & 976 & 525 & 0.018 & 75,643 \\
DE & 93 & 52 & 24,255 & 8036 & 376 & 1390 & 940 & 0.0191 & 77,553 \\
\hline
\end{tabular}

Table 6 Compare the results of different scenarios

\begin{tabular}{lcrllllll}
\hline & $\mathrm{A}_{\mathrm{PV}}\left(\mathrm{m}^{2}\right)$ & $\mathrm{A}_{\mathrm{W}}\left(\mathrm{m}^{2}\right)$ & $\mathrm{Eb}(\mathrm{KWh} /$ year $)$ & $\mathrm{C}_{\mathrm{a}}(\$)$ & $\mathrm{SCOC}(\$)$ & $\mathrm{I}_{\mathrm{a}}(\$)$ & LPSP & $\mathrm{C}_{\mathrm{T}}(\$)$ \\
\hline Base & 0 & 0 & 45,624 & 17,456 & 839 & 0 & 0.0368 & 220,747 \\
Scenario 1 & 0 & 138 & 26,145 & 8691 & 657 & 689 & 0.0198 & 87,956 \\
Scenario 2 & 121 & 0 & 27,700 & 9664 & 685 & 1593 & 0.02 & 176,291 \\
Scenario 3 & 80 & 63 & 23,853 & 7872 & 226 & 1192 & 0.0182 & 75,105 \\
\hline
\end{tabular}

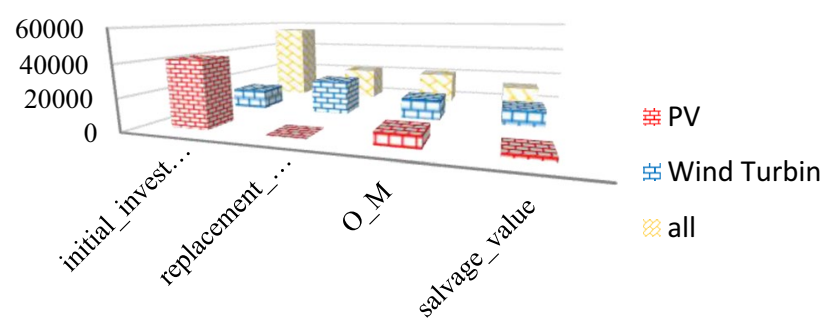

Fig. 12 Comparison of hybrid system costs

The sale of surplus equipment and surplus energy to the network are system revenues that are shown in a negative graph (income), and other items that are costing are plotted with positive outcomes. As shown, the purchase of energy shortage from the network has the largest share of the final cost of the system, and the initial installation of equipment is in the second order of cost.

\section{Conclusion}

In this paper, the optimal design of the hybrid power generation system in Sari has been studied. The main objective of this study is to provide a model for designing a hybrid power generation system that uses solar cell panels and wind turbines. Designs are implemented in such a way that the total cost of the system reaches its minimum. These costs can be the cost of initial investment, the cost of maintenance, the cost of purchasing energy from the grid, and so on. To this end, the BA algorithm was used to achieve this goal and the results were compared with the results of DE algorithms and PSO. In order to carry out studies, the actual sample system, whose data has been available, has been studied. Using the geographic location of the area, the amount of sun radiation and wind speed is obtained from NASA's site. Then, studies have been conducted in three scenarios. In the first scenario, the system only includes wind turbines. The final system cost was $192,908 \$$. In the second scenario, the only energy sources of solar panels are the system, with a final system cost of $17,691 \$$. In the third scenario, the combination of a solar-wind system has been used to provide power. The total cost of the system in this scenario is estimated at $171,489 \$$. The results of this section indicate that the hybrid system has a better performance than the other two scenarios in terms of the objective function (total cost of the system), and the scenario of the solar panel is better after the hybrid mode.
Fig. 13 Comparison of cost and system revenues in hybrid mode

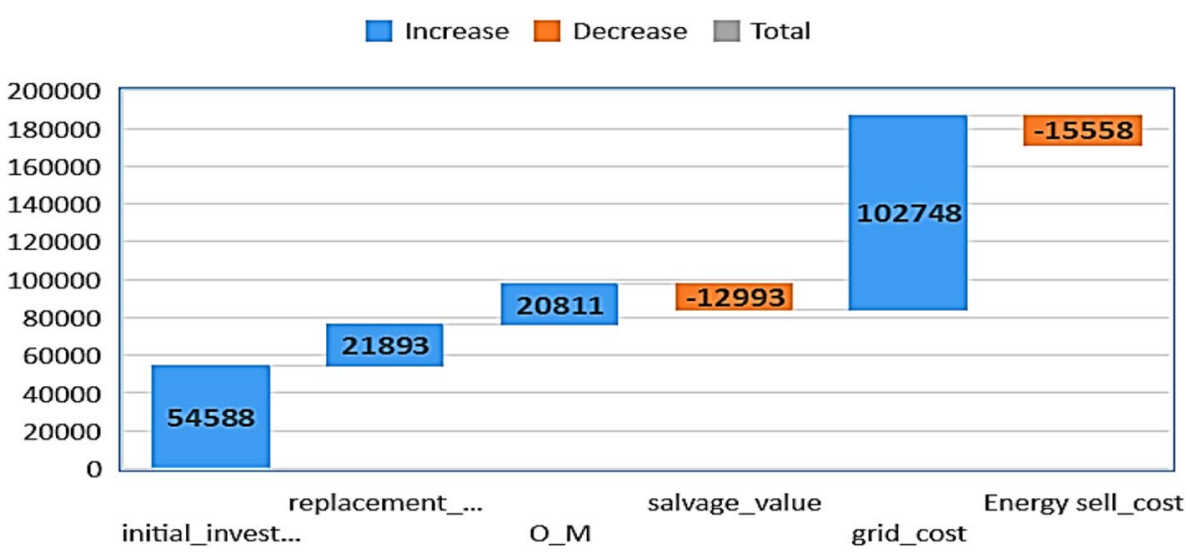


Comparison of the energy that each house requests per year in different scenarios shows that according to the prediction of the hybrid scenario with 23,853 kilowatt hours per year, it is less than the other scenarios, and unlike the overall cost of energy demand from the network in the wind scenario the solar scenario is less.

\section{Compliance with ethical standards}

Conflict of interest The authors declare that they have no competing interests.

\section{Appendix}

See Tables 7 and 8.
Table 7 System parameter values

\begin{tabular}{llll}
\hline Amount & Unit & Parameter symbol & Parameter title \\
\hline $1 / 0$ & & $\mathbf{r}$ & Interest rate \\
$04 / 0$ & & $\delta$ & Inflation \\
$075 / 0$ & & $\varepsilon_{P V}$ and $\varepsilon_{W}$ & Annual increase in operating and maintenance costs \\
25 & Year & $\mathbf{N}$ & Lifetime of the project \\
$9 / 0$ & & $\eta_{i n V}$ & Inverter efficiency \\
$7 / 519$ & $\$ / m^{2}$ & $\Delta$ & The initial cost of the solar panel \\
$1 \%$ off $\alpha_{P V}$ & $\$ / m^{2}$ & $\alpha_{O M P V}$ & The annual cost of operating and maintaining a solar panel \\
$25 \%$ off $\alpha_{P V}$ & $\$ / m^{2}$ & $\mathbf{S}_{\mathbf{P V}}$ & Solar panel sales price \\
25 & Year & $\mathbf{L}_{\mathbf{P V}}$ & Solar life span \\
$14 / 0$ & & $\eta_{P V}$ & Solar Panel Efficiency \\
$2 / 544$ & $\$ / m^{2}$ & $\alpha_{W}$ & The initial cost of the wind generator \\
$2 \%$ off $\alpha_{W}$ & $\$ / m^{2}$ & $\alpha_{O M W}$ & Annual cost of operation and maintenance of wind turbines \\
$30 \%$ off $\alpha_{W}$ & $\$ / m^{2}$ & $\mathbf{S}_{\mathbf{W}}$ & Wind turbine sales price \\
20 & $Y e a r$ & $\mathbf{L}_{\mathbf{W}}$ & Lifetime of wind turbine \\
$85 / 0$ & & $\eta$ & Efficiency \\
$59 / 0$ & & $\mathbf{C}_{\mathbf{P}}$ & Power factor \\
$225 / 1$ & $\mathrm{~kg} / \mathrm{m}^{3}$ & $\rho_{a}$ & Air concentration \\
\hline
\end{tabular}

Table 8 Energy retail price

\begin{tabular}{lll}
\hline Monthly consumption & $\begin{array}{l}\text { Consumption inter- } \\
\text { val (kWh) }\end{array}$ & Price $(\mathrm{kWh} / \$)$ \\
\hline Less than $75 \mathrm{kWh}$ & $0-50$ & $1196 / 0$ \\
& $50-75$ & $2649 / 0$ \\
75 kWh and more & $0-10$ & $1196 / 0$ \\
& $10-75$ & $2649 / 0$ \\
& Larger than 75 & $4402 / 0$ \\
\hline
\end{tabular}




\section{References}

1. Anoune K, Bouya M, Laknizi A, Abdellah AB, Astito A, Ghazouani $M$ (2019) Techno-economic investigation of solar-wind potential to power an industrial prototype using a hybrid renewable energy system. SN Appl Sci 1(11):1313

2. Maleki A (2019) Optimal operation of a grid-connected fuel cell based combined heat and power systems using particle swarm optimisation for residential sector. Int J Ambient Energy 252:1-8

3. Maleki A, Hajinezhad A, Rosen MA (2016) Modeling and optimal design of an off-grid hybrid system for electricity generation using various biodiesel fuels: a case study for Davarzan, Iran. Biofuels 7(6):699-712

4. Klychev SI, Mukhammadiev MM, Zakhidov RA, Potaenko KD (2007) Technical and economic conditions for creation of combined solar-wind power plants. Appl Solar Energy 43(4):214-217

5. Kazmi SWS, Sheikh MI (2019) Hybrid geothermal-PV-wind system for a village in Pakistan". SN Appl Sci 1(7):754

6. Zhang W, Maleki A, Rosen MA (2019) A heuristic-based approach for optimizing a small independent solar and wind hybrid power scheme incorporating load forecasting. J Clean Prod 241:117920

7. Maleki A, Pourfayaz F (2015) Optimal sizing of autonomous hybrid photovoltaic/wind/battery power system with LPSP technology by using evolutionary algorithms. Sol Energy 115:471-483

8. Zhang W, Maleki A, Rosen MA, Liu J (2019) Sizing a stand-alone solar-wind-hydrogen energy system using weather forecasting and a hybrid search optimization algorithm. Energy Convers Manag 180:609-621

9. Ding Z, Hou H, Yu G, Hu E, Duan L, Zhao J (2019) Performance analysis of a wind-solar hybrid power generation system. Energy Convers Manag 181:223-234

10. Zhang G, Wu B, Maleki A, Zhang W (2018) Simulated annealingchaotic search algorithm based optimization of reverse osmosis hybrid desalination system driven by wind and solar energies. Sol Energy 173:964-975
11. Chauhan A, Saini R (2014) A review on integrated renewable energy system based power generation for stand-alone applications: configurations, storage options, sizing methodologies and control. Renew Sustain Energy Rev 38:99-120

12. Caballero F, Sauma E, Yanine F (2013) Business optimal design of a grid-connected hybrid PV (photovoltaic)- wind energy system without energy storage for an Easter Island's block. Appl Energy 61:248-261

13. Fetanat $A$, Khorasaninejad $E$ (2015) Size optimization for hybrid photovoltaic-wind energy system using ant colony optimization for continuous domains based integer programming. Appl Soft Comput 31:196-209

14. Gan LK, Shek JKH, Mueller MA (2016) Optimised operation of an off-grid hybrid winddiesel-battery system using genetic algorithm. Energy Convers Manag 126:446-462

15. Bahmani-Firouzi B, Azizipanah-Abarghooee R (2014) Optimal sizing of battery energy storage for micro-grid operation management using a new improved bat algorithm. Int J Electr Power Energy Syst 56:42-54

16. Aman MM, Jasmon GB, Bakar AHA, Mokhlis H (2014) A new approach for optimum simultaneous multi-DG distributed generation units placement and sizing based on maximization of system loadability using HPSO (hybrid particle swarm optimization) algorithm. Energy 66:202-215

17. Theo WL, Lim JS, Ho WS, Hashim H, Lee CT (2017) Review of distributed generation (DG) system planning and optimisation techniques: comparison of numerical and mathematical modelling methods. Renew Sustain Energy Rev 67:531-573

18. Pham DT, Castellani M (2015) A comparative study of the bees algorithm as a tool for function optimisation. Cogent Eng 2:109-115

19. Nasrinpour HR, Massah Bavani A, Teshnehlab M (2017) Grouped bees algorithm: a grouped version of the bees algorithm. Computers $6: 1-12$

Publisher's Note Springer Nature remains neutral with regard to jurisdictional claims in published maps and institutional affiliations. 